\title{
Routine Breakers for Emotionally Active Learning: A Case Study
}

\author{
Rosa Munoz-Luna ${ }^{1} \&$ Antonio Jurado-Navas ${ }^{2}$ \\ ${ }^{1}$ University of Málaga, Spain \\ ${ }^{2}$ Metro-Access and Short Range Systems, Department of Photonics Engineering, Akademivej, Building 358, \\ DK-2800 Kgs. Lyngby (Denmark) \\ Correspondence: Antonio Jurado-Navas, Metro-Access and Short Range Systems, Department of Photonics \\ Engineering, Akademivej, Building 358, DK-2800 Kgs. Lyngby (Denmark)
}

Received: August 20, 2016

Accepted: September 10, 2016

Online Published: September 13, 2016

doi:10.5430/ijhe.v5n4p52

URL: http://dx.doi.org/10.5430/ijhe.v5n4p52

\begin{abstract}
The present paper aims to present a typology of classroom activities which may serve as group driving dynamics to improve student attention in class. Human attention skills may have been shortened now and traditional ways of imparting knowledge should be modified (Soslau, 2015). As a consequence, this implies multi-tasking behaviour as users develop a sense of immediacy. At the same time, student attention span is shorter at school and it decreases after certain time in the classroom doing monotonous activities. In order to find teaching solutions to this problem, we present what we call routine breakers, that is, classroom activities and catalysts with which to improve and optimise learner attention. We present students' feedback and routine breaker results in the form of a case study: overt classroom observations in a group of undergraduate students in a Spanish university. The practice of these attention-catching exercises, accompanied by a number of changes in the teaching routine, renders a typology of routine breakers which is described in this study. When comparing a traditionally held class and a session with routine breakers, study participants rate the latter more positively. Further pedagogical implementations are also suggested.
\end{abstract}

Keywords: Attention, Motivation, Routine-breaker, Observation, Classroom, Activity

\section{Introduction}

\subsection{Breaking the Traditional Concept of Teaching in Higher Education}

It is beyond question that the role of the teacher is more than that of teaching. Teaching is more than communicating knowledge from teacher to students; of course, much more than lecturing and slideshows. According to Thomas Shuell (1986), who brought a teacher-centred perspective, the instructor's main task is to get students to engage in learning activities that are likely to result in their achieving of the course objectives. De Hei et al. (2015) however highlighted the role of the learner when they stated that the behaviour of the student is essential in their own learning: what the student does becomes more important in acquiring new knowledge than what the teacher does. Nevertheless, the environment and dynamics a teacher creates in their classroom may still be a differential factor between good and bad teachers. It is such climate the background that students need to effectively engage in the different classroom activities.

In the teaching process, whether it is more traditionally conceived or more modernly so, capturing (and maintaining) students' attention is always a challenge. We have been working for the past eight years in the Spanish university classrooms that student concentration span becomes shorter. In this period of time we have realized that students feel the constant urge of checking their mobile phones or finishing several tasks simultaneously on their computers. That situation seems to be extended since it is detected the same problem in Denmark where one of the authors has been teaching. For this reason, we present a series of pedagogical resources to facilitate class dynamics regarding learners' attention and time management. Routine breakers (Muñoz-Luna, 2014) are a different way of motivating and keeping attention alive during the class. This paper aims to provide a range of learning opportunities for both teachers and students so that classroom quality time increases. In opposition to traditional methods employed in class, routine breakers divide all of them into smaller time segments with the purpose of holding student attention. The theoretical framework described in this paper, together with the routine breaker proposals we suggest, are the result of our own teaching experiences. 


\subsection{Macrocontext: Mapping the Terrain}

Traditional school learning is inexorably giving in to a new type of school learning with the purpose of maximising quality time between teachers and students. The integration of technological media, videos, collaborative learning or project based learning, critical thinking development and emotional intelligence implies the development of student competences which go further from the mere accumulation of encyclopaedic knowledge (Soslau, 2015). According to Pérez Gómez (2012), these competences can be summarized as:

- The competence of employing and communicating knowledge in an ordered and rational way, critically and creatively (rational and artistic mind)

- The competence of living and co-living in human groups which are gradually more heterogeneous (ethical and social mind)

- The competence of think, live and act autonomously (personal mind)

The emergence of digital technologies has also affected students' concentration and working rhythm (Downes, et al., 2016): learners tend to stop an activity and change it constantly. According to these authors, because of the increasing use of technologies in the classroom, the way knowledge is imparted must be changed. Students' attention spans are shorter, and so sessions have to be more dynamic and dialogic. Such alteration in work dynamics has undoubtedly affected the way lessons have to be planned, designed and implemented in a particular time and space. Student competences should therefore be achieved in a different way, according to more recent students' requirements.

The relationship between quality time and learning quality has been traditionally linked by researchers (Cotton, 1995); quality time devoted to certain contents and activities produces high-quality learning. Cognitive concentration on the task is important for students to interact effectively and according to their levels of competence development, no matter in what type of session they are participating: lecture, master class, seminar, inductive teaching, dialogue-based teaching, discovery learning, role play, or complex problem solving in group dynamics (Biggs, 2011; Prince, 2006). In this complex and varied teaching context, we propose the implementation of certain classroom routines which will help to alleviate long teaching sessions. These are activities which can be applicable to all session types and ages, however, we will focus on undergraduate students in the field of the Humanities, which is the group in which our experiment was implemented. These activities outcomes have also been shared with a group of colleagues during an in-service teacher-training course at the universities where the authors work.

\subsection{Microcontext: Student Attention during the Sessions}

Attention levels in class are easy to maintain when students are motivated about the subject they are studying (De Hei, et al., 2015). However, even those motivated learners need extra support after a certain time sitting in class. Attention levels and concentration decrease considerably after some minutes, and for that reason both teachers' and students' work is distorted. This effect is even more dramatic in those situations in which the learner's role is restricted to maintain an utterly passive attitude towards the subject and the teacher who is imparting a master class. In fact, researchers show that student levels of attention decrease drastically after fifteen minutes in class (Muñoz Luna, 2014). As a consequence, students are capable of retaining a lower amount of information, as Figure 1 shows (Hartley \& Davies, 1978):

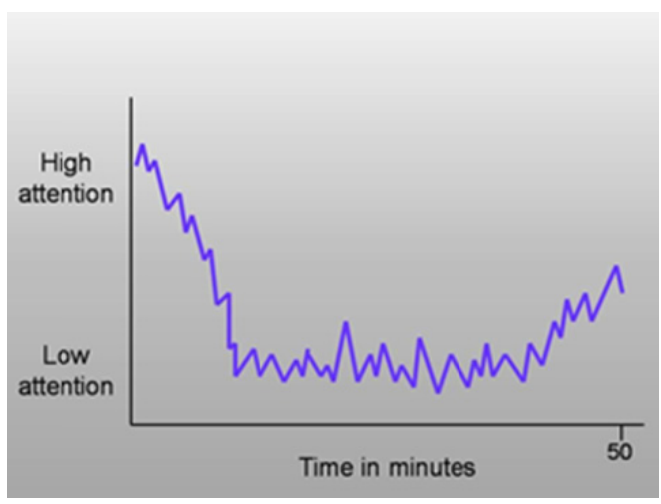

Figure 1. Students' attention levels in class in relation to time variables (Hartley \& Davies, 1978). 
In order to find a solution to this inevitable attention deficit, Hartley and Davies suggested to fragment, in the case of a lecture, the session into smaller units with the aim of having students connected to the contents at all times. The proposal the authors made was embedding active learning periods in the middle of longer sessions in which students normally had passive roles (Shea and Bidjerano, 2009). From this idea we suggest a change that affects all student groups and teaching types, that is, even active students in class need a change of rhythm after some time of attention to the teacher. This change does not necessarily have to be a break, a stop in the activity to do nothing, it can actually boost students' learning by promoting other types of activities in the classroom. As will be described later on, we propose several routine breakers in the classroom whose aim is to engage students emotionally and during the teaching session.

\subsection{Theoretical Framework and Hypothesis: Breaking Attention Spans to Attract Students'Attention}

The idea behind attention spans is closely related to the so-called microlectures, that is, shorter periods of time devoted to only one specific topic. According to Kong (2015), master classes fragments should not be longer than 18 minutes (neither should video or audio fragments be). This more dynamic session structuring leads to the development of critical thinking skills. Students transform their own experience into knowledge by acting on and using information that they are learning. If teachers give them time to think about their own learning in class, such learning process will be more meaningful and context-related (Nakatani, 2005; Niezgoda \& Röver, 2001). As teachers, the fact of devoting more time to thinking skills might imply student-focused teaching, where it is the student themselves who think and create their own contents (with the teacher's supervision). Such a delegation process could come in the form of routine breakers, as explained below, where learners should provide their own examples of a particular theoretical construct or extrapolate a new context from a given case.

Time devoted to critical thinking in class is sometimes hard to find by the teacher, who usually needs all the sessions to advance with the contents and course objectives. However, routine breakers can provide this time for thinking, as well as time for assimilating what has been previously explained in the class. After a routine breaker, it is a good moment to introduce more abstract or theoretical concepts of the subjects as attention levels have been restored again (Muñoz-Luna, 2014). We propose to following example: a type of routine breaker that could be inserted after 18 minutes of lecture could be a class discussion (this was one of the multiple routine breaker examples we implemented in our class to activate students, as explained below). In this case, the teacher proceeds in the following way: firstly, we ask a question, allowing the students to discuss among themselves and to formulate answers. Then, we show the question on a slide and immediately, we start to walk around the classroom while listening to the students. We stop this class discussion when the noise level drops, just to summarise in plenum and, after that, we can continue with our class by introducing new concept.

In addition to the option described above, where teachers leave some moments to reflect upon new knowledge, another variant could be applied: at the moment when we detect a high level of sonority in the classroom (student debates reach their zenit), teachers interrupt them and introduce a new concept that can be particularly difficult to understand. Later on, students can make a summary of their corresponding debates. These phases of teacher-student interaction typically occur in transformative learning (Nohl, 2015). In this case, teachers would have worked on more complex issues when students' attention was high (learners were paying attention again after the discussion routine breaker). As we have indicated, these are examples to engage the students during the longest period of time possible during lessons.

As for the rationale behind such theoretical framework, finding time for thinking, debating and catching attention in the classroom is related to the training of competences. As Pozo and Pérez Echeverría (2009) propose, the previous ideas are inherent to the process of modernisation of European universities. Teaching students to develop their competences shape them into better professionals. In this regard, López-Pastor, et al. (2011) examine the importance of teacher training programmes on the basis of action-research frameworks. According to the latter, students become more aware of the course evaluation process if they are intentionally immersed in action-research activities.

\section{Method}

Classrooms are particularly complex universes where human beings interact playing different roles; for this reason, observers have to be aware of the high amount of variables interfering their observations and which are not the main focus of their study.

In this paper, we are detailing some features and circumstances of a concrete course of English Studies at a southern Spanish university following a case study methodology because we are describing and analyzing the particular situation of this course (Ary, Jacobs and Razavieh, 2009, 456) in the academic year 2014-2015 to show how the routine breakers were developed to promote an active learning, complementing other papers published by the 
scientific community (Muñoz-Luna, 2014; Soslau, 2015).

For the data collection process in the present study we chose unstructured observation (Dörnyei, 2007, 179), that is, completing narrative field notes supplemented by diagrams and outlines. Detailed descriptions immediately followed the observations, and at the same time we noted down our first qualitative analyses from the situations observed. From those observation diaries the main categories and variables emerged, upon which we draw our discussion (see Table 1). In addition, we work under the action research framework (Lewin, 1946; Kember \& Kelly, 1993; McNiff, 2013); the nature of this study is twofold: while we teach, we implement this investigation in which the main objective is to improve student attention span. The obtained feedback from students is essential in this methodology in order to assess the accomplishment of the objective. Informed consent was obtained from the participants prior to the beginning of this study.

Table 1. Sample of narrative diary (unstructured observations) written by the authors during the sessions.

Session number 3 (1 hour 20 min.)

Student-initiated participation 5 instances

Student participation initiated by the teacher 18 instances

\begin{abstract}
Attention levels before routine breaker
Sessions starts with students paying attention normally. After about 25 minutes, attention decreases. We can see students check their phones, some even go to the toilet or just move on their seats. Most of them look at the teacher and seem to know what she is saying, but their level of participation is lower.

Some of them ask for clarification, something that doesn't happen at the beginning of the session.
\end{abstract}

\title{
Attention levels after routine breaker
}

Students seem refreshed, as if the session was about to start again. Their faces are relaxed and smiling. We can see they take deep breaths. They start taking notes again in a better mood.

\section{Type of routine breaker}

Physical. Students get up and move around the class looking for their matching pair. They sit in other places and do a short activity ( 8 minutes) on the theory they have just learned before.

\section{Attitude of students during routine breaker They all participate eagerly.}

Extra comments Physical routine breakers are useful when students are not physically tired at the end of the day.

\subsection{Ethical Considerations}

As commented above, ethical aspects were considered throughout this study. In accordance with the Code of Ethics and Conduct (BPS, 2009), the aim of the research and interview method was explained to the participants and the informed consent was obtained from them prior to the beginning of this study. Confidentiality and privacy was completely guaranteed. The current study is made in a qualitative manner (study case) and no names nor other personal affiliations were provided through this manuscript.

\subsection{Participant Characteristics}

Observations were made during every lesson of the subject "Lengua Avanzada" (i.e. English grammar) at a southern Spanish university during autumn-winter semester 2014-2015. Participants were a group of 40 undergraduate students of English Studies who gave their consent to be part of classroom observations by their teachers (the authors of this paper); they were aware of the new teaching methodology implemented but were not conscious of the rationale behind it or the purpose. During six hours every week students attended these lessons and participated in the different proposed activities (each lesson being 90 minute long). This experience was shared and explained during an in-service teacher training course, having the opportunity of even implementing some of the routine breakers with the teacher group. We used observation sheets where we noted down significant changes in behaviour of students during the lessons. Those observation sheets included relevant changes in student participation (frequency and length of participation in class) as well as modifications in their attitudes and motivation. Such 
observations were registered regarding the class group as a whole as well as the particular instances of student interactions (student-teacher, student-student). As a way to measure routine breaker impact, we interviewed students before and after the activities were implemented (that is, at the beginning and at the end of the term, once the exams were finished and they had received their marks on the subject). Interviews were conducted in the teacher's office, with an average duration of 20 minutes; once students knew this was part of a research project, each of them received a number according to the participation list arranged in alphabetical order. Only those who volunteered were interviewed, conforming a 60 percent of the total amount of students $(\mathrm{N}=24)$. Regarding data reduction, we chose the most representative responses and those we considered singular). Prior to the interviews, students were told that their anonymity was going to be preserved, and that those interviews were part of the research project we were involved in (concerning the use of routine breakers in the classroom). Interview questions are the following:

- How long do you think you can pay attention to the teacher in class (in minutes)?

- What activates your attention during a lecture?

- How do you think you learn better in class (in terms of classroom activities)?

\subsection{Sampling Procedures}

On the basis of our action-research teaching, we have classified routine breakers in terms of duration of realisation. Therefore, we can talk about short routine breakers when we refer to those activities which are class catalysts with a duration of 3-5 minutes. Longer routine breakers imply more time in class devoted to them. Longer routine breakers might also involve peer-correction/evaluation practices of an activity previously done in the class (or at home).

Within the latter, we have implemented the following routine breakers to engage students in the classroom:

(1) Poster session: after bringing some homework from the previous day, students have to work in small groups; homework correction would take place as in a poster session. In this manner, each group would inform the rest of the class about their findings and reflections. This activity was implemented during the usual class time, and each student group had to evaluate the other two groups. The rest of the time would be devoted to see other classmates' posters. Learners were requested to follow the 3 Cs rules when providing their feedback: be constructive, caring and concrete (Andersen et al., 2012)

(2) Co-teaching: in this case, we offered students the possibility of preparing some particular subject content and exposing it in pairs to the rest of the class. We also co-taught the in-service teacher training course in which these routine breakers ideas were explained. This idea is an adaptation by the authors from dialogue-based teaching methods (Vella, 1980; Vella, 2007), where teachers were holding a dialogic conversation between them. There are differences in pitch, tones, and teaching styles, as well as different viewpoints offered to students. As a consequence, learners' attention moves from one teacher/speaker to the other with the same intensity and sense of novelty, so much needed to hold attention

(3) Pyramid or Snowball technique: this is a technique based on the exchange of ideas. Students must work individually first on a particular topic, and next in couples for some minutes. After discussing with another couple, the four of them will discuss with other members, and so on, finishing a discussion involving all the students in the class. This technique promotes other skills in students such as critical thinking, reflection, dialogue, analytical skills and agreement. Each group/pair must agree on the idea that their group will defend in the class. At the end of the activity, the group must have a common answer to the proposed problem

These longer routine breakers were inserted after 18 minutes of lecturing. In some cases, lessons began with a long routine breaker (lasting around 15 minutes), then the lecture followed just to finish the session with another routine breaker at the end. As examples of short routine breakers (3-5 minute long), there are different types of routine breakers:

(1) Physical routine breakers: university master classes (supported by power points or any other visual materials) are interrupted by shorter activities involving pair work and the changing of student places to work with other classmates. In some cases, it involves discussing a theoretical concept previously seen with another partner, and then applying it to a context that is close to the students reality. In physical routine breakers, there is no need of a thematic rupture in the flow of the lesson but a physical change happens instead; students will work with somebody who is not sitting next to them, therefore, they have to change places and move around the classroom

In the teaching of a foreign language, the use of physical motivation is the perfect ground for the teaching of phonology, for instance. An example is the particular gestures (mouth and face movements) that the teacher can ask their students to do. By visualising sounds (vowels and consonants in a foreign language), learners produce them 
more accurately: teacher and students perform different sounds in the class, for example closing their mouths and smiling, pronouncing a vowel, then opening their mouths slowly, rounding the lips, etc. Making students pronounce words not in isolation but as a string of sounds which merge and form diphthongs, weak and strong sounds, etc. Focusing on form rather than on meaning allows students to work, examine and analyse physiological characteristics of sounds. As a result of the previous activities, we obtain the benefits of both focusing the attention on something different and improving pronunciation qualitatively. The focus on meaning rather than on form was not part of the initial syllabus of the subject, and the inclusion of such aspect in the classroom provided students with practical grounds where to practise pronunciation.

Another physical routine breaker example is asking students to stand up and form groups with different classmates from the ones they have around them. Teachers can help in the forming of the groups by giving students cardboard pieces randomly with the names of possible groups (A, B, C...) so that students group themselves and discuss a particular topic among them.

(2) Thematic routine breakers: the teacher proposes a radical change in the topic they are dealing with in the classroom. For instance, a different activity can be initiated, homework can be corrected, student interactions triggered, etc. These are about different topics indirectly related to the course subject: study techniques, career plans or motivation strategies, or even the latest news in the country, which might me related to the course contents.

Another example of this type of thematic routine breakers is the delivery of assignments by the teacher, who has corrected some homework handed in by the students some days before. This short activity becomes an effective routine breaker in which students are given some feedback on their own submitted work.

Thematic routine breakers can also provide an insight into academic work procedures. Portfolios, as for instance Mahara online platform (Mahara, 2015) works as an example of a new digital environment in which students and teacher can share their progress. Displaying this new tool in the class and proposing some activity in it is a way to switch their attention from the normal flow of the session to something different, but still academic. Mahara Portfolio combines the teaching principles that are needed for a project-based learning methodology (Markham, 2011): cooperation and information spreading. Mahara is constructed on the basis of sharing contents, knowledge and information with others, compiling the rules of social networks. Moreover, Mahara resembles the working procedures of companies where team members have to work together to reach an aim. When students perceive and assimilate the concordance between what they do in class and what they will be doing out of it, their learning becomes more meaningful. At the same time, learners' learning opportunities become professional rehearsals. In this case, Mahara was students' communication and working online framework: they uploaded their reports and progress there, teachers provided feedback, students shared resources, and all of that resembles the working environment they will have in their future careers.

(3) Non-thematic routine breakers: these routine breakers do not offer a new topic to debate. By following the same topic previously discussed in class, we can ask students to discuss upon a proposed issue in small groups; later on, they can explain their ideas and conclusions to the rest of the class.

A more dynamic option implies the use of clickers such as the ones proposed by OMBEA (2015), which allow students to respond to a multiple-choice question formulated in class by the teacher. Results are computerised and shown immediately on the projector screen, and then all participants in the class can see the different answers and comment on the correct one. If the collected results are varied, the teacher can propose small group discussions with the aim of sharing all the different answers and discussing the various viewpoints. In some cases, a second round applies to see whether the answers have changed.

(4) Student self-assessment: it presents a twofold purpose. On the one hand, class dynamics are changed, and on the other, teachers obtain valuable information about course content, materials, teaching procedures, etc. Assessment surveys can be implemented both at the beginning and at the end of the course. These information-gathering tools provide a valuable insight of students' initial perceptions of the subject, the teacher and the group. When used at the end of the subject, they are helpful to collect final impressions and opinions regarding the course development, as well as future lines of improvement.

\section{Results}

Routine breakers are excellent strategies to work on learners' positive attitude towards the subject, their academic performance and expectations. It is always useful to remind students that very often the difference between a preferred and a non-preferred subject (one that they like and another they do not) is the attitude they possess towards them, the peculiarities of the teacher and students' personal skills, as observed in the classroom. In this line, routine 
breakers provide a novel and pleasant background where to boost learners' positive attitude and confidence within the group.

The most relevant result of our study coincides with the objective of routine breaker implementation in the classroom: routine is broken intermittently and students' attention is always active, avoiding boredom and demotivation. The rupture in the routine is quite abrupt, so students must change from one activity to the other one with no time for adaptation. The new activity will be new and limited in time, and that is the reason why they are on the alert; we believe such cognitive state improves attention:

\section{"I felt as if I was on the alert during the class; always expecting something interesting to happen in the form of a fun activity". Student 31 .}

Changes like these are perceived positively by students, who enjoy moving around the class in search for a new working partner, or just debating about some specific content from an innovative perspective. As we observed in the sessions, students' attitude when physically moving from one place to another in class improved, partly due to the so needed physical movement after some time on their seats (longer routine breakers, where physical movement was implied, were implemented after longer teaching spans of around 30 minutes).

Routine breakers help students and teachers to be more communicative with each other. Teachers ask questions and they have the opportunity to express themselves and also to be less shy concerning question posing during the class. In these observations, students grouped in pairs or small groups during routine breakers were prone to participate more than when they were working individually; we observed openness in their attitude when they were being supported by a peer. Because of students' change in attitude and their more active participation in class, we claim that routine breakers are of a high importance in students' education because these breaks help their academic progress in the following ways: improving their academic results thanks to motivation and more practical skills, fast learning of new concepts and increasing their attention focus. Finally, these interruptions also motivate teachers to change the traditional form of teaching and make the classes more manageable and rewarding for both, students and professors. From a qualitative perspective, and taking into consideration participants' opinions about the experience, we have selected some impressions as follows:
"When it comes to talk about classes' development, I think almost most of students mention the word 'monotonous'. We tend to think very often that the majority of classes are maybe too theoretical that it seems they are always the same: teachers just always talking and talking about the subject and students listening and 'paying attention' to them. Of course, that does not mean that we might not enjoy the subject, that we do not want to pay attention or that it is the teacher's fault, for instance. Things have been different with this experience, where all the importance has been placed onto practice”. Student 3.
"Sometimes students really like a subject and feel motivated about it but in the end it is not what they thought of it for various reasons. It is at this point when I think routine breakers are very important". Student 4.
"Prolonged attention in a class is something that nowadays is hard to achieve. Students are often attentive at the beginning of the class but this attention decreases as the class progresses. If they have to pay attention to a theoretical class for 90 minutes, it is almost sure that a high percentage of the class would be looking at their mobile phones or thinking about other things. This is then something that affects both students and teachers in the sense that both would perhaps feel tired after long sessions". Student 8.

Participants seem to coincide in the fact that sessions which are too theoretical are more monotonous and harder to follow. When interruptions are made systematically, and those interruptions focus on practice, students employ theory in practice and thus the former becomes more meaningful for them. In some other cases, routine breakers turn a particular subject into something more appealing, not because of the mere contents, but because of the classroom 
dynamics they create.

It has been demonstrated that what attracts students to the subject is practical exercises. These exercises help the leaners understand the theory easily and allow them to rely on that theory and to examine how it works in real life. Practice can also work as an attempt of what students will have to face in their future careers. Regarding the duration and the frequency of routine breakers, they should be as long and as frequent as the teacher may feel that will benefit the students. We all have different individual needs, but as a group we are different as well, each group of students may need a particular type of resources to enjoy the subject as much as possible. As a significant part of the experience, it is worth noting that students liked to be asked about their opinion and to have a committed teacher in class.

The selection of students' responses in this paper has been made following criteria of repetition and relevance (i.e. those answers commonly repeated by students have been selected). The rest of the answers not included in this paper are also in a similar line with the main ideas presented, but they are shorter or they present less evidence of the students' claims. As for the questionnaire answers by participants, these are the responses by the students before the implementation of routine breakers in the sessions:

(On their attention span in class) "It really depends on the subject. Sometimes I feel I lose track after 10 minutes of the session. With other teachers, I can stay attentive for longer because they use examples and jokes while they talk; that helps. I think I have the tendency to be on the alert whenever something important is going to happen in the classroom". Student 22.

(On what activates their attention) "It is very well known that you might fall asleep when the teacher's voice is monotonous, right? A sudden change in their voice activates you, or a change in the intonation, also if another student takes in". Student 18.

(On the activities to learn better in class) "My favourite activities in the classroom are those with are fun or involve being active in some way. I also like thinking that what I am doing in class will be useful in the future professional career. That is crucial to motivate me". Student 31.

After the routine breakers were introduced in the sessions, at the end of the semester and after the examinations (to avoid possible conditioning of the students), they answered the questionnaire again, and these are some of the most relevant responses:

(On their attention span in class) "I have changed my perception of attention spans in the classroom after using routine breakers. The fact of having a break in the flow of the class motivates me and also the knowing that a break will come. For that reason, I can stay on the alert for longer. When I felt tired, after maybe 20 minutes of class, the teacher initiated a different activity". Student 28.

(On what activates their attention) "Routine breaker activities have activated my attention in class. I have realised that by doing different exercises I feel more motivated and I am able to feel active. Having the opinions of other classmates does also motivate me, as I get to know different viewpoints. Physical movements in the class as well as changes in the subject topic is also good to activate your attention". Student 14.

(On the activities to learn better in class) "All the different students have different preferences in the classroom, I think. For example, some people prefer working in groups while others like working on their own. Routine breakers are good because they provide different contexts and styles each time: working in pairs, group discussions, learning about something different from the subject. The key is definitely in the change”. Student 9. 


\section{Discussion: Pedagogical Implications}

Due to their name, we may think that what makes routine breakers a good tool in classes is the opportunity that they bring to forget the subject and relax for some minutes. Nonetheless, what is most interesting of the concept of routine breakers is that they represent a way to make students be interested in a particular theme without making them feel overwhelmed. Students' perception is that routine breakers can be implemented in different ways, e.g. proposing a theme and making the students form a particular opinion and defend it in class. This would encourage them to participate in the class as well as open their minds to find new solutions to problems and creating new ideas. Consequently, both students' attainment and class attendance improved; as they state, they feel more motivated about the subject, which is no longer so theoretical, and which presents new opportunities for learning.

Multimedia resources are also believed to attract pupils' attention as they feel identified with these new means of researching and looking for information; YouTube videos, Wikipedia, blogs, movies or book excerpts can be proposed as examples or even as part of the topics. Knowledge, abilities, skills, affect (emotions), autonomy, happiness, motivation, involvement, dynamics, etc. are the elements that are fully present in the development of routine breakers. In addition, these activities are not always purely cognitive (mental) but they can be physical, also introduced by means of routine breakers. Students' attention and implication are active at all times during the session thanks to these breaks in the class routine.

Routine breaker as a concept is something students have not normally heard about in class before. Both teachers and students are aware of routine breaker usefulness when they experience positive outcomes of their implementation. Most teachers, to a greater or lesser extent, employ classroom dynamics techniques to increase students' attention levels and motivation in the classroom. However, it is only when these routine breakers are introduced systematically that we assimilate them as part of the very routine, yet as they are different each time, these breaks are not monotonous.

Although we are aware of how much theory a subject contains, if the teacher provides students with practical exercises, or time to discover/induct/apply knowledge, or uses images and presentations in the session, it is more probable that we would feel more motivated and willing to learn more of the subject. Not to mention that we would retain the information better and for a longer time.

Our findings coincide with the latest results of academic research on the use of multimedia in the classroom to enhance student attention (Shea and Bidjerano, 2009; Kong, 2015). The periodic change of activity in the classroom favours academic performance and student interaction (among themselves and with their teacher).

\section{Concluding Remarks}

There are several kinds of routine breakers that do not need to be related to the subject. For example, apart from the ones mentioned above, some of the ones we did in class were about advices or tips for exams of any subject, study techniques or professional job opportunities related to linguistics or any other subject in our career. Encouraging students to participate and generate a debate, showing audio-visual content related with the topics or even conduct experiments and research in which a particular aspect of the subject is shown are believed to be some of the best solutions to impart an alluring lecture. All these techniques can be compressed into routine breakers.

In addition, other types of routine breakers can be carried out to improve some skills: conferences in which students show their research can also help them to lose their fear to speak in public. Group assignments can teach them to collaborate or to be imaginative; and the interchange of information with other universities (or schools) can make them find new ideas and help them to be outside their comfort zone.

Thus, routine breakers, in our opinion, provide a very effective solution to the attention-failure problem in the following ways: if a change in the dynamics of the class suddenly takes place in the middle of the session, it will attract student's attention towards the teacher more often and maintain it during the whole lesson.

\section{Acknowledgements}

The authors want to give special thanks to all the students participating in this study, and to the reviewers and proofreaders of earlier forms of this paper.

\section{References}

Andersen, B.A., Mulbjerg, I., Møller, E., Nielsen, M. \& Vadmand, O. (2012). At loere - En håndbog $i$ studiekompetence. Copenhagen: Samfundslitteratur.

Ary, D., Jacobs, L. C., Razavieh, A. \& Sorensen, C. K. (2009). Introduction to Research in Education. Belmont: 
Wadsworth Publishing; 8 ed.

Biggs, J. \& Tang, C. (2011). Teaching for quality learning at University. New York, NY: McGraw Hill.

BPS (British Psychology Society) (2006). Code of ethics and conduct. Retrived Septembert 10, 2016 from http://www.bps.org.uk/the-society/code-of-conduct/code-of-conduct_home.cfm

Cotton, K. (1995). Effective schooling practices: a research synthesis. Portland: Northwest Regional Educational Laboratory.

De Hei, M., Strijbos, J., Sjoer, E. \& Admiraal, W. (2015). Collaborative learning in higher education: lecturers' practices and beliefs. Research Papers in Education, 30(2), 232-247. http://dx.doi.org/10.1080/02671522.2014.908407.

Downes, J., Bishop, P., Swallow, M., Olofson, M. \& Hennessey, S. (2016). Collaborative action research for middle grades improvement. Educational action research, 24(2). http://dx.doi.org/10.1080/09650792.2015.1058169.

Dörnyei, Z. (2007). Research methods in applied linguistics. Oxford: Oxford University Press.

Educause. (2012). Things you should know about microlectures. Retrieved from: http://www.educause.edu/library/resources/7-things-you-should-know-about-microlectures/.

Hartley, J. \& Davies, I. (1978). Note taking: a critical review. Programmed learning and educational technology, 15, 207-224. http://dx.doi.org/10.1080/0033039780150305

Kember, D. \& Kelly, M. (1993). Improving teaching through action research. Campbelltown, NSW: Higher Education Research and Development Society of Australasia.

Kong, S. C. (2015). An experience of a three-year study on the development of critical thinking skills in flipped secondary classrooms with pedagogical and technological support. Computers and Education, 89, 16-31. http://dx.doi.org/10.1016/j.compedu.2015.08.017.

Lewin, K. (1946). Action research and minority problems. Journal of Social Issues, 2(4), 34-46. http://dx.doi.org/10.1111/j.1540-4560.1946.tb02295.x

López-Pastor, V.M., Monjas, R. \& Manrique, J.C. (2011). Fifteen years of action research as professional development: seeking more collaborative, useful and democratic systems for teachers. Educational Action Research, 19(2), 153-170. http://dx.doi.org/10.1080/09650792.2011.569190.

Mahara open source eportfolios. (2015). Retrieved from: https://mahara.org/.

Markham, T. (2011). Project Based Learning: a bridge just far enough. Teacher Librarian, 39(2), 38-42.

McNiff, J. (2013). Action research. Principles and practice. New York: Routledge.

Muñoz-Luna, R. (2014). Enhancing language learners' motivation: the use of routine breakers with undergraduates learning English linguistics. Bellaterra Journal of Teaching and Learning Language and Literature, 7(1), 33-51. http://dx.doi.org/10.5565/rev/jt13.513

Nakatani, Y. (2005). The Effects of Awareness Raising Training on Oral Communication Strategy Use. The Modern Language Journal, 89, 76-91. http://dx.doi.org/ 10.1111/j.0026-7902.2005.00266.x

Niezgoda, K. \& Röver, C. (2001). Pragmatic and Grammatical Awareness. In K. Rose \& G. Kasper (Eds.). Pragmatics in Language Teaching (pp. 63-79). Cambridge: Cambridge University Press. http://dx.doi.org/10.1017/CBO9781139524797.008

Nohl, A. (2015). Typical Phases of Transformative Learning: A Practice-Based Model. Adult Education Quarterly, 65(1), 35-49. http://dx.doi.org/10.1177/0741713614558582.

Ombea. (2015). Retrieved from: http://www.ombea.com/gb/.

Pérez Gómez, Á. (2012). Educarse en la era digital. Madrid: Siglo XXI.

Pozo, J.A. \& Pérez Echeverría, M.P. (Coords.) (2009). Psicología del aprendizaje universitario: la formación en competencias. Madrid: Ediciones Morata.

Prince, M.J. \& Felder, R. (2006). Inductive teaching and learning methods: definitions, comparisons, and research bases. Journal of Engineering Education, 95(2), 123-138. http://dx.doi.org/ 10.1002/j.2168-9830.2006.tb00884.x

Shea, P. \& Bidjerano, T. (2009). Community of inquiry as a theoretical framework to foster epistemic engagement and cognitive presence in online education. Computers and education, 52(3), 543-553. 
http://dx.doi.org/10.1016/j.compedu.2008.10.007

Shuell, T. J. (1986). Cognitive conceptions of learning. Review of Educational Research, 56(4), $411-436$. http://dx.doi.org/10.3102/00346543056004411

Soslau, E. (2015). Student-teachers' emotional needs and dichotomous problem-solving: non-cognitive root causes of teaching and learning problems. Educational action research, 1747-5075. http://dx.doi.org/10.1080/09650792.2015.1072052.

Vella, J. (1980). Learning to listen: a field guide to methods of nonformal education. Massachusetts: University of Massachusetts.

Vella, J. (2007). On teaching and learning: putting the principles and practices of dialogue education into action. Hoboken: John Willey \& Sons.

Wankat, P. (2002). The effective efficient professor: teaching, scholarship and service. Boston: Allyn and Bacon.

\section{Notes}

Note 1. The present paper has been funded by the National Research Project Grant $(\mathrm{I}+\mathrm{D}+\mathrm{i})$ "Emoción y Lenguaje en Acción". Such project is hereby gratefully acknowledged. 